\title{
REFLEXÕES SOBRE AS CIÊNCIAS SOCIAIS NA ATUALIDADE
}

Osmar Ossis Gobatto *

\section{Resumo:}

O marxismo no seu conceito filosófico da história é determinista, e não possibilita que o processo histórico tenha tendências, não sendo poșsível relacioná-lo ao imaginário e ao simbólico. Por outro lado, Weber abriu caminhos demonstrando que as teorias das ciências sociais não são permanentes, e que a racionalização e a intelectualidade contribuíram para o desencanto do mundo, sendo que, a ciência e a técnica forçaram o homem a não aceitar os valores do espírito, do sagrado e do imaginário. Mesmo assim, a racionalização não conseguiu destruir a importância do irracional, ao contrário, aumentou a sua força. Dessa forma, a intuição não pode ser científica porque está condicionada ao imprevisível, ou seja, ao irracional. A sociologia compreensiva weberiana abriu perspectivas para que a sociologia interagisse com outras ciências, e que o sentido subjetivo de valores dependem de nossos desejos, sentimentos e conflitos existentes na racionalidade. Quanto mais as ciências sociais avançam, mais dúvidas surgem, assim, todo o conjunto conceitual e teórico da atualidade fundamentado no racionalismo e determinismo entrou em crise. A compatilização atual é entre o imaginário/simbólico e o lógico/racional, existindo uma reciprocidade entre o concreto e o abstrato, relacionando-os e possibilitando a formação de um conhecimento da própria realidade.

\section{Palavras-chave:}

Ciência, determinista, imaginário, irracional, lógico, marxismo, racional, simbólico e weberiano.

O materialismo dialético pode ser considerado como concepção filosófica marxista inspirada na dialética hegeliana, cuja origem está condicionada a um sentido ideal e relacionada a uma forma de apreensão voltada ao economicismo. É contrário ao movimento mecanicista da história, aplicando um sentido intercessor entre a causa e efeito, demonstrando, igualmente, que as contradições internas constituem sua transformação.

Em relação ao conhecimento, o materialismo dialético justifica que o ser está acima de sua consciência, apontando que o sentido ontológico concreto sobrepõe-se à consciência, mostrando que as categorias econômicas é que infundem a ligação prática do homem ao significado do seu objetivo Sobre o materialismo dialético,

\footnotetext{
* Mestrando em Sociologia no Programa de Pós-Graduação da Faculdade de Ciência e Letras da UNESP - Araraquara/SP. Professor do Departamento de Ciências Hunanas e Sociais da UNIARA.
} 
Marx (1985, p.20), no prefácio da segunda edição do Capital, afirma: "Por sua fundamentação, meu método dialético não só difere do hegeliano, mas também da sua antítese direta. Para Hegel, o processo do pensamento que ele, sob o nome de idéia, transforma num sujeito autônomo, é o demiurgo do real, real que constitui apenas a sua manifestação externa. Para mim, ao contrário, o ideal não é nada mais que o material, transposto e traduzido na cabeça do homem".

O materialismo dialético, quando empregado sobre os seres humanos, forma o materialismo-histórico, sendo que o seu ponto fundamental é aquele que diz que o ser social determina a consciência social e resulta na atividade material por intermédio do trabalho, que vem a ser o arcabouço da organização social.

A filosofia marxista da história é determinista e não possibilita que os acontecimentos históricos possam ter tendências. Assim, a história não produz teorias e conceitos definitivos, mas permite o seu continuísmo de realização e transformação dentro do seu contexto.

Apesar de toda importância e influência que o materialismo histórico exerceu sobre as ciências sociais, é difícil encontrar uma justificativa conceitual para relacionála a uma explicação, a partir do imaginário e do simbólico de uma realidade histórica. $\mathrm{Na}$ análise de um processo histórico, o imaginário está ligado ao entendimento e à compreensão da cultura e da experiência humana. No entanto, o marxismo como ideologia, na afirmação de Castoriadis (1982), é "um conjunto de idéias que se refere a uma realidade não para esclarecê-la e transformá-la, mas para encobri-la e justificála no imaginário".

Em relação a Weber, o seu grande mérito, quanto à sua teoria sociológica, é verificar que não há possibilidade de abranger todo o conhecimento numa verdade universal e permanente. Assim, é possível, através da intuição, aplicar infinitas variáveis para se ter uma compreensão de uma realidade empírica. Outra grande contribuição weberiana é aquela de se estabelecer a posição da ciência voltada para a ação, onde o homem encontra o melhor caminho para compreender o seu objetivo. A ação e o conhecimento desenvolvidos pelo homem nunca são plenamente realizados, porque é necessário elaborar novas formas de ação e novos conhecimentos.

O pensamento weberiano, dessa forma, é contrário a qualquer tipo de sistema, porque, a partir do momento em que define suas teorias e conceitos, passa a ter certeza de que construiu conhecimentos científicos definitivos, no entanto: "No domínio da ciência, ao contrário, cada um sabe que sua obra terá envelhecido daqui a dez, vinte ou cinqüenta anos... É que toda obra científica "concluída" não tem outro sentido, a não ser o de fazer surgirem novas perguntas: ela pede, pois, para ser "ultrapassada", e para envelhecer. Quem quer servir à ciência deve conformar-se com esta sorte" (Weber, 1970, p.214).

Dessa maneira, para ele, não se deve ter nenhuma teoria preconcebida e nem formular conclusão apriorística. Todo conhecimento científico deve ser analisado com profundidade, no intuito de se ter uma avaliação segura e de acordo com suas 
possibilidades de entendimento.

Mesmo com toda a sua radionalidade, o homem tem a conviç̧ão de que nada s. pennanente de que mäo pode estar separado de sua insegurança e incerceza, centro de sua reflexão, porque, a cada momento ou epoca, a realidade se aransfoma, conduzindo a novas fomas de atitudes e conbecimentos cientificos que podem ser aceitos on rejeitados.

A êffase na racionalidade e na intelectualizaçăo contribuiu para o desencanto do mundo. Segundo Weber a ciência e técnica forçaram o homem a não aceitar mais os valores do espírito, da magia, do sagrado e do imagináro. Assim, a racionalizaça, com todo o seu desenvol vimento, năo conseguiu destruir a impontância do irracional: "A contránio, com a racionaliziço crescente, o inacional se reforça com intensidade" (Freund, 1970, p.71).

Na sua concepçāo. Weber afima que o conhecimento não tem condiços de se afigurar como reproduçio do real, pois o real e "infinto e inesgotátel" e que seria impossivel alcançar a adoça de quatquer método, porque comportatia uma qualificą̧o infinita de soluçöes da realidade. Desse modo a intuição nắo pode ser considerada como conhecimento científico, porque ela pertence ao dominio do sentimento esta condicionada ao imprevisivel, ou seja, ao imacional. Dentro da irracionalidade, todos of valores dependem de uma avaliaçäo, estäo condicionados a nossa percepcio e ao desejo, onde o conhecimento näo existe.

Todos os valores que sito ressahados numa analise cienffica tem seus significados que devem ser interpretados com a finalidade de esclarecer quais os seus fundamentos. Todo tipo de conhecimento deve ser testado experimentado, tendo em vista o relacionamento qque se antrelaçam as valores pesquisados. Dessa forma, e possível desprezar aquilo que năo se coaduna com os objetivos interpretados.

Na opinião de Weber. valido lançar măo de leis gerais e mesmo da compreensaio do individuo no direcionamento da pesquisa cientifica. tentando captar a realidade nas suas mais variadas formas possiveis. A sociologia pode utilezar quaisquer meios de análise que possibilitam aumentar o conhecimento cientiffoc.

A sochogia compreensiva de Weber é a tendencia de mostrar que a sociologia. as vezes, näo kern condiçöes de esclarecer e interpretar todos os aspectos de uma realidade social, mas contribui para o alargamento conceituat da sociologia tradicional.

Qualquer sociedade formada por uma serie de relacionamentos, de contribuiģoes, de conflitos e de sentimentos que se manifestam e interagem dentro das mais variadas esferas sociais, políticas, economicas ou religiosas. Assim, para Weber, todas as ciencias devem tre interacoes entre si, porque, na verdade, ê a compresnsio gue capacita a apreensäo do sentido de uma aço on atividade: "Entendemos por atividade um comportamento humano (pouco importa que se trate de un exterior ou interior, de uma omissĩo ou de uma tolerância sempre que um agente ou os agentes the comunicam um sentido subjetiva. Por atividade social antendemos a que, segando o sentido visado, o agente ou os agentes relacionam com 
ocomportamento de outrem para orientat en consequencia. setu desenvolvimento" (Freund, 1970, p.80).

O importante que se percebe na sociologia de Webré que ela representam ponto importante dentro da interpretaçito do conhecinento aentifico. Isso norgue ela coloca en evidêneta o sentido subjetivo, além de apresentar a compreensäio do conhecimento ciansal de uma at vidude. Pana Weber a ciencia năo pode desenvolver

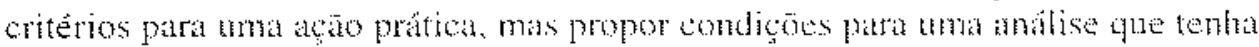
possibilidades de consegur alcançar o objetivo. pots: "Em suma uma clênein empirica nào está apta a ensinar a ninguén aquilo que "deve". mas sim, apenas que "pode"e - encertis circunstâncias - itgtito que "quer fazer" (Cohn, 1921, p.21).

Quando Weber declarou que a racionalidade e a renta desencantaram o mudo, por outro lado. eje abrin caminhos a perspectivas para que a sociologia rivesse condiços de se interagir com outus ciencias, possibilitanto uma mulidisciplinardade e. também. uma avaliaça compreen iva do sentido subjetivo de valores que dependem de nowsos dekejos, sentimentos e conflitos existentes rat racionalidate.

Nöo é somente na socledade atual que encontrantos uma diversificaçio de culuras, de antagonismos e de comportamentos, mas também mas ditudes individuats, colocando-os em confronto com seus semelhantes. produzindo diferentes persmalidades. Na realidade tudo isso pode revelar a identidade humana dentro de cadaindividuo.

Esse ser complexo, desamparado. e, as vezes, desestruturado na sta cxistencia moura em certas teoriax do conhecimento alternativas que o conduzim it al guma seruranch. Mas, pelu que se obsorva, os novos conhecimentos cientificos produzem movas inseguranças c, quanto mais st desenvolvem as ciencias, mas duvidak se formam na identidade do homen.

Todo o conjunto conceitual e térico cientifico da atualidade que está

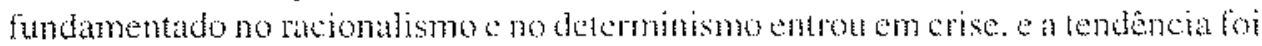
uma compatbilizaçăo entre o imaginúrio/simbótico e o lógico/racional a fim de que os conceitos pudessem ser aplicados na interpretaçăo da realidade pois: "A nossa

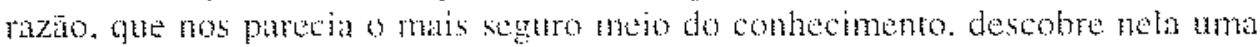
manchan negra" (Morin. 1991. jr.l3\}.

Na busca da verdade. o ser humano se defronta com a incompresento do conhecimento que se revela num amontondo de interrogacooss as quais nos conduzem a própria ignornencia do conthecimento.

Para Morin. o conhecimento ś um "fenômeno multidimensional" que se relaciona se antagoniza con toda uma série de categorias incoporadas na cogntę̆o humata. produzindo fratura c que induzem a formato do conhecineno.

O conhecimento a a ciencia estato em crise: nem o ampirsmo e a logica constituem bases pura conhecimento. chega-se entuo: "à descoberta de que nuo hí nonhum fundamento certo para oconhecimento que este comporta sombras. zonas 
cegas, buracos negros" (Morin, 1991, p.19).

Se o conhecimento está em crise, então se abre a possibilidade para o conhecimento do conhecimento, cuja origem se remete a filosofia de Kant eque. atuatmente, pode e deve fer um sentido cientifico, alem de possibilitar seu carater filosófico. Nota-se, também, que a filosofia a ciência não possuem condiçōes para compreender o conhecimento. e que a solução não é produzir uma "metafilosofia", mas propiciar um método no sentido de superar as dificuldades entre a ciencia e a filosolia.

Para Morin, at racionalidade deve se valer da analogia, porque atsim serí possivel a constituiçáo de motetos e formas, desde que possam ser testadas atraves da deduçăo do empirismo. Dessa maneira, existe una reciprocidade entre o concreto e o abstrato, relacionando-os a possibilitando a formaço de um conhecimento da própria experiência.

Quando se evidencia o sixnificado da compreensio na analise de uma reatiode, verificamos que podemos inseri-la como participante do conhecimento em geral, onde a subjerividade e atetividade assumem posiçoes que se tomam indispensaveis. a lim de que o conhecimento possa se fundamentar atraves da compreensäo.

Por sua vez, a explicagào de um simoma com objetividade e meionalidate se relaciona com a compreensão e se completa, pois: "A compreensão e a explicação são a mesmo tempo contidas uma ma outm, opostas e complementares (yin-yang). Về-las-emos en açăo nos dois grandes sistemas do pensamento, que tamberm sairmm da mesma fonte contidos um no outro, opostos e complementares: o pensamento simbólico/mitológico/mágico eo pensamento empiricológico/racional" (Morin. 1991 , p. 143 ).

É possivel a verificaça de que existe ma difetença entre estes dois modelos de sistema do conhecimento, mas tamberm se constata que ambos se complementam através de uma rede intrincada de situnçōes sem deturparem suas findidades.

Mesmo com todo o avanç que a ciência e a lecnica liveram nos úttimos tempos, não foi possivel a extinçäo, ou nesmo, a reduçăo da influencia mítica, simbólica ou religiosa das atividades do ser humano. O que se verifica é que essas manifestaçoses estä́ impregnadas na racionalidade e no conhecimento científico. on seja, f uma situagăo "antropossocial fundamental" ma afimaçăo de Morin. Os conhecimentos míticos e simbólicos estāo tamberm em interaçăo, e, em complementaridade, um dependendo do otro.

O conhecimento racionalempírico/técnico está fundanentado nama realidade objetivo, ao passo que o conhecimento simbólico/mitológico/mágico está voludo para o subjetivo, mas compreensivamente é possivel uma superaça e commicaçäo entre ambos, interagindo e complementando os seus aspectos opostos porque: "Temos uma necessidade imperiosa da correção empírical logica/racional sobre todas as atividades mentais, mas, também, temos uma necessidade vital do lecido imaginario/simbolico que co-tece a nossa realidade 
e de que são feitos os mitos: "We such stuff as drems are made". O pensamento racional precisa do seu duplo" (Morin, 1991, p.164-5).

\begin{abstract}
:
The Marxism in its philosophy conception by history is determinated, and don't possibility that the history process have been tendences, it's not being possible to associate at imaginary and symbolic. In other size, Weber maked the way, showing us that the theory by the social science don't be permanence, and which rationalizacion and intelectuality contributed for a desilution world, however, science and tecnic compeled the man to not accept the value spirits by the sacret and imaginary . Nevertheless, the rationalization couldn't destroy the rational importance, instead of, increased your power. In this case, the intuition can't be scientific because it be condicioned by the imprevisible, in others words, the irrational . The Comprehensible Weberian sociology opened perspectives by sociology procced by others sciences, and that the subjective feeling about values depends of our desires, feelings and conflits exists in rationality. As more as the science avanced, more hesitation appears, this, all the concept and theory social collection by atualitty based in racinonalism and determinism came in crisis, the compatilization actual is between the imaginary/symbolic and logic/rational, living a reciprocity among the concret and abstract, to relacioning them by the formation.
\end{abstract}

Keywords:

Science, determinism, imaginary, irrational, logic, marxism, rational, symbolic and weberian.

\title{
Referências bibliográficas:
}

CASTORIADIS, Cornelius. A instituição imaginária da sociedade. Rio de Janeiro: Paz e Terra, 1982.

FREUND, Julien. Sociologia de Max Weber. Rio de Janeiro: Forense, 1970.

MARX, Karl. Introdução à crítica da economia política. São Paulo: Nova Cultural, 1985.

O capital. São Paulo: Nova Cultural, v. 1, 1985.

MORIN, E. O método. Publicações Europa-América. Portugal, v. III e IV,1991.

WEBER, Max. Metodologia das Ciências Sociais. Maurício Tragtenberg (org.). São Paulo: Cortez, 1993.

COHN, Gabriel (org.). Weber. São Paulo: Ática,v.13, 1991.(coleção grandes cientistas sociais) 